\title{
POÉTICAS CRIMINALES: REFLEXIONES TEÓRICAS DE ESCRITORES DE NOVELA NEGRA Y POLICIACA
}

\author{
Javier SÁNCHEZ ZAPATERO
}

Universidad de Salamanca

zapa@usal.es

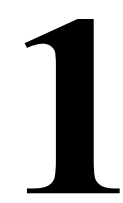

\section{El estudio del género negro y policiaco}

Durante buena parte del siglo XX, el estudio de la narrativa popular ha estado vetado en el ámbito académico. Entre las causas que han motivado su exclusión del canon pueden citarse algunas estrictamente literarias -la mayor importancia de lo argumental sobre lo formal, la recurrencia a la estereotipación y al uso de fórmulas hasta llegar a hacer de la lectura un acto casi ritual basado en el reconocimiento de los mismos tópicos y el mismo esquematismo reiterativo, cierta tendencia a la simplificación, etc.- y otras relacionadas con la dimensión pragmática de los textos basados en su condición de producto de masas, en el hecho de haber sido consumidos durante mucho tiempo de forma casi exclusiva por las clases populares o en la idea de que «con frecuencia la narrativa popular se ha concebido como un instrumento de preservación de la ideología dominante, mientras que a la literatura "seria" se le pide que cuestione constantemente la percepción e instrumentalización de los valores que la sociedad ha institucionalizado» (González de la Aleja, 1999: 7)-1․ Así se demuestra en el caso de la narrativa negra y policiaca, cuyo alejamiento de las instituciones culturales y académicas de referencia habría venido provocado, más allá de por sus características temáticas y formales o por su mero valor artístico, por su surgimiento, vinculado al folletín y a la prensa; por su estrecha relación con manifestaciones artísticas que también han sufrido durante mucho el descrédito de las elites culturales como el cine o el cómic; y por el fervor del que desde prácticamente sus inicios gozó entre el público lector, del que resulta especialmente sintomático el caso de Sherlock Holmes, convertido en auténtico icono de masas en el Reino Unido durante las últimas décadas del siglo XIX y las primeras del XX. De hecho, durante mucho tiempo la novela negra y policiaca fue «reducida a la categoría de género ínfimo», hasta el punto de que «reconocer su lectura (a escondidas) resultaba avergonzante [y] era impensable que pudiera ser objeto de atención académica seria» (Colmeiro, 1994: 15), creándose así una barrera entre las obras demandadas por el público y las difundidas desde la

\footnotetext{
${ }^{1}$ En cierto modo, estas últimas razones podrían verse como una consecuencia de la crítica de Adorno y Horkheimer (1944) a la reproductibilidad de las formas artísticas modernas, puesto que tendrían como premisa «la semejanza de la llamada literatura de género con los productos industriales» y, en consecuencia, la aproximación de «su escritura a la cadena de producción de la industria moderna» (Resina, 1994: 13).
} 
universidad y otras instituciones canonizadoras. De forma muy esclarecedora, Stephen King denominó a estos dos tipos de literatura «wannaread»y «gottaread» (1981), mientras que Sullá estableció todo un catálogo terminológico para referirse a ella: para los textos que se engloban en la primera, «apócrifos, subliteratura, literatura light, popular, de consumo, periférica, de difusión masiva, infraliteratura, paraliteratura, o simplemente no literatura»; para los de la segunda, «canónicos, clásicos, auténticos, ejemplares, maestros, inmortales, consagrados» (1998: 24).

Pese a que en la actualidad la novela negra y policiaca -y, en general, casi todas las muestras de narrativa popular- parece haber superado ese desprecio que la condenaba a ser una forma literaria de rango inferior, integrándose de forma progresiva en el ámbito académico y siendo objeto de un proceso de normalización ${ }^{2}$, el mantenimiento de los prejuicios elitistas durante tanto tiempo ha tenido varias consecuencias. Entre ellas, destaca de forma especial la ausencia de textos de teoría, crítica e historiografía literarias dedicados a la narrativa negra y policiaca, con evidentes excepciones como las que representan, por ejemplo, las aproximaciones al género de emblemáticos pensadores como Tzvetan Todorov o Umberto Eco. Semejante carencia ha repercutido de forma muy negativa en los enfoques analíticos que durante las últimas décadas se han fijado en el género, que han tenido que sentar las bases de su estudio sin disponer de una tradición académica previa ni de un corpus fijado, y con la necesidad de crear terminologías y taxonomías específicas. No en vano, más allá de cierta crítica impresionista llevada a cabo más por aficionados que por especialistas, prácticamente los únicos acercamientos teóricos llevados a cabo durante hasta la segunda mitad del siglo XX fueron realizados por algunos autores que complementaron su labor de creación con reflexiones sobre lo que estaban escribiendo y que, a modo de arte poética y con una muy clara conciencia de representar un tipo de literatura diferente a la considerada canónica, intentaron definir las principales características del género narrativo en el que se imbricaba su obra.

\section{Edgar Allan Poe y el prefacio de Los crímenes de la calle Morgue}

Tradicionalmente, la crítica especializada ha situado los orígenes del género policiaco en 1841, fecha de publicación de Los crímenes de la calle Morgue (The Murders in the Rue Morgue). El relato de Edgar Allan Poe, incluido en las páginas de la revista de Filadelfia Graham's Magazine, fue el primero de los tres que protagonizó August Dupin, cuya importancia, más allá de su carácter fundacional, residió en su capacidad para sentar las bases de los personajes detectivescos del género, caracterizados desde entonces por su elevada e inusitada capacidad intelectual, una personalidad altanera que les hacía jactarse de sus virtudes y cierta artificiosidad que les llevaba a presentarse como epítomes de la razón más que como reflejos verosímiles de los modelos humanos de la realidad.

Según Javier Rodríguez Pequeño, Los crímenes de la calle Morgue «va a fijar la esencia del género policiaco, esto es, la resolución del misterio producido por un crimen mediante una

\footnotetext{
${ }^{2}$ En general, ese proceso normalizador está mucho más consolidado en los ambientes intelectuales y universitarios anglosajón y francófono que en el hispánico, que hasta la década de 1990 apenas contaba con publicaciones especializadas sobre el tema.
} 
investigación racional» (2008: 156). Sin embargo, nada nuevo hay en el relato, que se limita a aglutinar diversas características que ya habían ido apareciendo a lo largo de la historia de la literatura. Evidentemente, antes de Edgar Allan Poe habían sido muchos los autores que habían escrito sobre crímenes, misterios e investigaciones basadas en la racionalidad. La muerte violenta está presente en la literatura desde su surgimiento como tal, como demuestran paradigmáticas muestras como las de la Biblia o Edipo Rey, mientras que la tradición de novela gótica y de terror, bien conocida - y practicadapor Poe, había ido aportando todo un mundo de misterios sobrenaturales y fantasiosos. Y la deducción había aparecido, por ejemplo, en la obra de autores ilustrados que, como Voltaire con las historias protagonizadas por Zadig, utilizaron las creaciones de ficción para lanzar su mensaje de confianza absoluta en la razón como instrumento rector y ordenador del mundo.

No obstante, como ha señalado Del Monte, «aunque los elementos que han contribuido a dar forma al género negro existieran con anterioridad, no lo hacían como conjunto sino dispersos» (1962: 21). La novedad de la obra de Poe no está, por tanto, en lo que presenta, sino en cómo lo presenta, pues lo que da el carácter fundacional a Los crímenes de la calle Morgue es la combinación de tres elementos -«el crimen [...], el juego que plantea al lector [...] y la investigación que a través de criterios deductivos a resolver el misterio» (Martín, 2007: 26)- explícitamente manifestados en su trama argumental: dos mujeres han aparecido salvajemente asesinadas en una casa cuya puerta no estaba forzada y que, además, permanecía cerrada por dentro, con lo que el personaje investigador $-\mathrm{y}$ con él el lector, en una especie de competición intelectual- ha de averiguar quién es el asesino, cómo pudo entrar en la vivienda y ensañarse de forma tan cruel con las víctimas, y por qué cometió tal acto. A estas tres características conviene sumar la dimensión social desde la que la obra de Poe aborda el delito y la investigación. El factor lúdico no ha reducir el valor de las historias protagonizadas por Dupin a un mero pasatiempo ni ocultar que en ellas late una intención de crónica de una época y un espacio. Los relatos policiacos aportan una cosmovisión determinada y, aunque no contengan descripciones de referentes concretos, sí que poseen un valor de representación social, pues informan de los principios criterios rectores que determinadas elites intentan aplicar en la sociedad. Al presentar como esquema argumental básico un estado de cosas establecido perturbado por un hecho delictivo y solo repuesto tras una investigación basada en la fuerza de la razón, lo que transmiten las narraciones protagonizadas por Dupin -y todo el género que a partir de ellas se desarrolla- es la consolidación en la sociedad de una mentalidad positivista que, alejándose del irracionalismo romanticismo que incluso había caracterizado algunas de las creaciones anteriores del propio Poe, hacía prevalecer la deducción lógica como única forma de conocimiento.

El carácter novedoso de Los crímenes de la calle Morgue fue asumido por su propio autor, quien incluyó un breve prefacio metaliterario de tono ensayístico y reflexivo en el que se afirma que «el relato siguiente presentará para el lector algo así como un comentario de las afirmaciones que anteceden» (Poe, 1841: 10). De ese modo, se demuestra que la parte inicial de Los crímenes de la calle Morgue vendría a ser una declaración de intenciones, una poética personal en la que Poe pretende explicar teóricamente lo que va a desarrollar en la práctica en el relato. Así, por ejemplo, se afirma que 
el buen investigador analítico ha de ser «silencioso» y que tiene que «acumular cantidad de observaciones y deducciones», puesto que «la mayor o menor proporción de informaciones así obtenidas no reside tanto en la validez de la deducción como en la calidad de la observación: lo necesario consiste en saber "qué" se debe observar» (Poe, 1841: 8), lo que se corrobora en el relato con la actitud de Dupin. Su método de investigación no solo se basa en la deducción racional sino, sobre todo, en su capacidad de observación, como se manifiesta cuando el narrador homodiegético que le acompaña señala cómo al llegar a la casa en la que aparecieron los cadáveres el detective «lo inspeccionaba todo, sin exceptuar los cuerpos de las víctimas», hasta el punto de que «el examen nos tuvo ocupados hasta que oscureció, y era de noche cuando salimos» (Poe, 1841: 33) ${ }^{3}$. En el relato también se incide en la importancia de la razón cuando el propio protagonista, impresionado por lo extraño del caso al que se enfrenta, sostiene «que se considera insoluble este misterio por las mismísimas razones que deberían inducir a considerarlo fácilmente solucionable» (Poe, 1841: 33), confirmando con ello que subyacen al texto de Poe los postulados del positivismo -que, grosso modo, defendía que todos los fenómenos estaban relacionados mediante nexos lógicos y de causalidad- y del determinismo -que sostenía que los actos de la realidad, especialmente los derivados de los objetos naturales, obedecen a leyes que es posible conocer para, en consecuencia, prever lo que va a suceder. Es decir, lo que plantea Dupin, como símbolo del pensamiento antirromántico de la época, es que todo lo que sucede en la realidad ha de tener una explicación racional que el hombre, gracias a su inteligencia, ha de ser capaz de encontrar.

Además del método que ha de seguir y las características que ha de tener el buen investigador, en esa parte introductoria - a la que podría considerarse como el primer tratado teórico de género policiaco- se diserta sobre cómo «el analista halla su placer en esa actividad del espíritu consistente en desenredar [...]: le encantan los juegos, los acertijos, los jeroglíficos, y, al solucionarlos, muestra un grado de perspicacia que, para la mente humana, parece sobrenatural» (Poe, 1841: 12). Semejante afirmación evidencia la relevancia que en el género policiaco van a cobrar la ya citada deducción racional y la interacción con los lectores, a quien el relato plantea un desafío lúdico, desarrollando así un modelo argumental al que Javier Coma denominó con acierto «crucitrama» (1985: 13). En el relato de Poe hay una voluntad de «jugar» con el lector que confiere al género una de sus principales y más distintivas señas de identidad, puesto que quien que se adentra en la lectura lo hace con la convicción estar ante un reto deductivo, de forma que al interés intrínseco de la lectura se le suma el valor lúdico. Para Borges, de hecho, el gran logro de Poe al desarrollar el género policiaco fue crear un nuevo tipo de lector caracterizado por su actitud activa:

\footnotetext{
${ }^{3}$ El propio Dupin llega a señalar en uno de los diálogos del relato la necesidad del investigador de «saber mirar» para poder reconstruir lo sucedido: «Si se observa una estrella de una ojeada, oblicuamente, volviendo hacia ella la porción exterior de la retina (mucho más sensible a las impresiones luminosas débiles que la parte interior), se verá la estrella con claridad y se apreciará plenamente su brillo, el cual se empaña apenas la contemplamos “de lleno". Es verdad que en este último caso llegan a nuestros ojos mayor cantidad de rayos, pero la porción exterior posee una capacidad de recepción mucho más refinada. Por causa de una indebida profundidad confundimos y debilitamos el pensamiento, y Venus misma puede llegar a borrarse del firmamento si la escrutamos de manera demasiado sostenida, demasiado concretada o directa» (Poe, 1841: 31).
} 
Hay un tipo de lector actual, el lector de ficciones policiales. Ese lector ha sido-ese lector se encuentra en todos los países del mundo y se cuenta por millones- engendrado por Edgar Allan Poe. Vamos a suponer que no existe ese lector, o supongamos algo quizá más interesante; que se trata de una persona muy lejana de nosotros. Puede ser un persa, un malayo, un rústico, un niño, una persona a quien le dicen que el Quijote es una novela policial; vamos a suponer que ese hipotético personaje haya leído novelas policiales y empiece a leer el Quijote. Entonces, ¿qué lee?

En un lugar de la Mancha de cuyo nombre no quiero acordarme, no hace mucho tiempo vivía un hidalgo... ${ }^{4}$ y ya ese lector está lleno de sospechas, porque el lector de novelas policiales es un lector que lee con incredulidad, con suspicacias, una suspicacia especial.

Por ejemplo, si lee: En un lugar de la Mancha..., desde luego supone que aquello no sucedió en la Mancha. Luego: ... de cuyo nombre no quiero acordarme..., ¿por qué no quiso acordarse Cervantes? Porque sin duda Cervantes era el asesino, el culpable. Luego... no hace mucho tiempo... posiblemente lo que suceda no será tan aterrador como el futuro.

La novela policial ha creado un tipo especial de lector. Eso suele olvidarse cuando se juzga la obra de Poe; porque si Poe creó el relato policial, creó después el tipo de lector de ficciones policiales (1980: 82).

\section{Las reglas de la novela policiaca}

Lejos de ser baladí, la importancia de la interacción entre autor y lector en la novela policiaca está en la base de algunos de los textos teóricos que los escritores escribieron durante los primeros años del siglo XX, un periodo al que la crítica habitualmente se ha referido como la «edad de oro» (Alonso y Santamaría, 1997: 16) del género, estimulado gracias a la obra de autores como Gaston Leroux, Arthur Conan Doyle, Agatha Christie, Gilbert K. Chesterton, Edgar Wallace, Richard Austin Freeman, Hal Meredith o S.S. Van Dine. Precisamente este último, creador del detective Philo Vance, es el autor de uno de los más recordados tratados sobre novela policiaca, publicado en 1928 en las páginas de la revista American Magazine. Originalmente titulado «Twenty Rules for Writing Detective Story»-y habitualmente traducido como «normas» o «reglas», incidiendo así en su carácter prescriptivo $-^{5}$, el texto de Van Dine comienza definiendo las obras adscritas al género como «juego intelectual», e incluso como «acontecimiento deportivo» (1928). De este modo, se pone de manifiesto cómo al autor, al igual que a sus compañeros de generación, le interesa, por encima de otras cuestiones, el valor lúdico de sus narraciones, puesto que todo juego necesita, en primer lugar, unas reglas y, en segundo, unos participantes que las cumplan.

Tal y como han señalado Alonso y Santamaría, Van Dine «impone reglas destinadas a potenciar el juego limpio entre autor y lector, para que este último y el investigador cuenten con la misma información» (1997: 17), con lo que «la investigación policiaca [...] se convierte en el centro de gravedad de la historia», por encima de otras cuestiones como «largos pasajes descriptivos, [...] profusión de adornos literarios, [...] trabajados análisis de caracteres [o] preocupaciones atmosféricas». De hecho, en la decimosexta regla se recomienda explícitamente eliminar de la narración todos aquellos elementos que puedan entorpecer la acción e introducir «aspectos irrelevantes para el propósito principal, que es presentar un problema, analizarlo y llevarlo con éxito a una

\footnotetext{
${ }^{4}$ Aquí y en lo sucesivo, en cursiva en el original.

${ }^{5}$ En 1929, el autor británico Ronald Knox publicó, como prólogo a una compilación de relatos policiacos, un decálogo en el que resumía, reduciendo a diez, las normas de S. S. Van Dine.
} 
conclusión». También la cuarta regla refleja esta idea, al negar la posibilidad de que en una novela policiaca pueda haber una intriga amorosa, argumentado que «el asunto es llevar el criminal a manos de la justicia, no llevar a una enamorada pareja al altar del himeneo» (Van Dine, 1928).

Además de la necesidad de mantener la intriga criminal y de no ofrecer pistas falsas que puedan obstaculizar la posibilidad del lector de resolver el misterio $-\mathrm{y}$, por tanto, de competir con el investigador- ${ }^{6}$, el texto de Van Dine insiste en dos cuestiones que ya aparecían en el prefacio de Los crímenes de la calle Morgue. Por un lado, la quinta regla sostiene que «el culpable debe ser determinado por deducción lógica, no por accidente, coincidencia o confesión sin motivos», evidenciando así cómo el racionalismo y el determinismo subyacen a toda novela policiaca. Asimismo, en la octava regla se expone de forma explícita el carácter antirromántico del género, incapaz de admitir como forma de resolución de las intrigas «cábalas, lectura del pensamiento, sesiones espiritistas [o] bolas de cristal» $\mathrm{y}$, en general, cualquier método supersticioso o heurístico no basado de forma estricta en la racionalidad. Por otro lado, Van Dine utiliza sus normas para caracterizar e indicar cuál ha de ser el método de actuación del personaje investigador, cuya función, según se dice en la sexta regla, «es reunir pistas que deben conducir hasta la persona que cometió la fechoría; y si [...] no llega a su conclusión a través de un análisis de estas pistas, no habrá resuelto su problema mejor que el escolar que saca su respuesta sin demostrar el desarrollo aritmético» (1928), confirmando con ello su convencimiento en que cualquier acción puede ser reconstruida a partir de la observación y la aplicación del método deductivo.

Grosso modo, algunas de las ideas de Van Dine están presentes en el texto que escribió tres años antes Gilbert K. Chesterton Cómo escribir relatos policiacos (How To Write a Detetive Story, 1925). De forma menos sistemática -y también menos taxativa, presentando sus indicaciones más como consejos que como normas-, el autor británico también expone en ese texto su convencimiento en la necesidad de un «juego limpio» entre el escritor y el público al afirmar que «el arte verdadero consiste en colocar cosas que [el lector] pueda y deba entender, aunque no llegue a hacerlo»(1925: 28) y que, en consecuencia, no engañar, desviando las sospechas hacia personajes que no son culpables $u$ ocultando pistas relevantes para la resolución del caso, ha de ser la máxima principal que guíe a los creadores de novela policiaca: «si confundimos al lector de manera que no pueda encontrarle sentido a lo que lee, concluirá que no tiene sentido y dejará de leer» (1925: 33). Al igual que Van Dine, también Chesterton recomienda no utilizar como culpables sociedades secretas, mafias criminales, mayordomos, ni tampoco a los propios detectives, afirmando que los móviles del delito han de ser personales e «implicar en cierto modo al alma humana».

\footnotetext{
${ }^{6}$ Esta idea aparece reflejada en varias reglas: «1. El lector debe tener las mismas oportunidades que el detective para resolver el misterio. Todas las pistas deben ser perfectamente mostradas y descritas; 2 . El autor no puede tender al lector más trampa o distracción que las que el criminal tienda al detective protagonista; [...] 4. Ni el detective ni ninguno de los investigadores oficiales puede ser el culpable. Sería un truco demasiado bajo; [...] 11. Criados, mayordomos, lacayos, cocineros y otros empleados del hogar no pueden ser culpables. Es una solución demasiado fácil. Hará que el lector sienta que ha perdido el tiempo. El culpable debe ser una persona que valga la pena, de la que no hubiéramos sospechado jamás» (Van Dine, 1928).
} 
A pesar de la popularidad de este tipo de poéticas de carácter normativo, su repercusión en el proceso de creación literaria ha sido, en líneas generales, escasa, puesto que casi siempre han sido ignoradas. Para Colmeiro, la razón de esta transgresión «está en la necesidad central del género de causar sorpresa, de mantener en vilo al lector» (1994: 43) y, en cierto modo, de seguir evolucionando para garantizar su perpetuidad como forma narrativa evitando la fosilización y la homogeneización a las que le hubiera condenado la continua aplicación de reglas. Además, se ha de tener en cuanta que la condición de objeto cultural y humano de las obras literarias las confiere una unidad y singularidad que las hace incompatibles con cualquier tentativa prescriptiva. Ahora bien, la existencia de normativas como las de Van Dine resulta de suma utilidad para, en primer lugar, explicar la estereotipación y el progresivo alejamiento del realismo que caracteriza a la novela policiaca durante el primer cuarto del siglo XX; en segundo lugar, comprender los prejuicios y el rechazo de gran parte de la crítica y la academia, que, influidas por una concepción formalista e inmanente de la literatura, valoraban negativamente un género cultivado por unos autores que de forma explícita rechazaban cualquier preocupación por el estilo, la escritura o cualquier aspecto distinto a la mera construcción de la trama argumental de misterio; y, en tercer lugar, confirmar, gracias a la capacidad metaliteraria y autorreflexiva que evidencian, la rapidez con la que la novela policiaca se consolidó como género narrativo identificable y fuertemente codificado durante las últimas décadas del siglo XIX y las primeras del XX.

Pese al cambio sufrido por el género en la época contemporánea -manifestado, grosso modo, en el paso de la variante policiaca basada de forma exclusiva en la resolución de un enigma criminal a través de procesos deductivos a la variante negra, dotada de un mayor grado de realismo y crítica social-, han continuado apareciendo textos análogos a los de Van Dine y Chesterton. Ya no se plantean como prescripciones, sino, más bien, como consejos para escritores que quieran iniciarse en el género. Así, por ejemplo, Elmore Leonard o P. D. James han compuesto sendos listados en los que dan una serie de recomendaciones, de carácter fundamentalmente técnico, relacionadas con la forma de mantener la intriga, de crear personajes o de diseminar la información, en la línea de las indicaciones propias de las escuelas y los talleres de escritura creativa. También Borges y Bioy Casares escribieron sobre la cuestión, haciendo especial hincapié en la idea de que la solución al misterio planteado debía ser necesaria, pero también asombrosa, y rechazando el uso de cualquier «trampa» que pudiera despistar al lector. Y otros autores, como Patricia Highsmith o, en el ámbito hispánico, Andreu Martín, han publicado tratados en los que, combinando la experiencia personal con la reflexión sobre la teoría y la historia literarias, han diseccionado el proceso creador y la técnica narrativa del género para ofrecer una serie de consejos sobre cómo escribir. Sintomáticamente titulados Suspense. Cómo se escribe una novela de intriga (Plotting and Writing Suspense Fiction,1981) y Cómo escribo novela policiaca (2015), ambos pueden ser leídos, trascendiendo su valor práctico, como reflexiones sobre las características de la novela negra y policiaca. Mientras que el texto de Highsmith destaca, entre otras cosas, por su capacidad para integrar al género en la tradición narrativa, insistiendo en lo que le une a otro tipo de novelas y relatos, y no en sus características distintivas -«toda narración que conste de un 
Poéticas criminales: reflexiones teóricas de escritores de novela negra y policíaca

principio, una mitad y un final tiene suspense; es de suponer que una narración de suspense se llama así porque tiene más [...] [y porque contiene] una amenaza de violencia y peligro» (Highsmith, 1981: 9), llega a decir en las páginas iniciales-, el de Martín lo hace por el hecho de compilar muchos de las reflexiones, sistematizadas o no, que los escritores de narrativa negra y policiaca han hecho sobre su creación.

\section{Raymond Chandler y El simple arte de matar}

La publicación de El simple arte de matar (The Simple Art of Murder, 1944) ${ }^{7}$ resulta especialmente importante tanto por el hecho de provenir de un destacado y reconocido pionero de la novela negra como por su valor fundacional. En cierto modo, podría decirse que el texto de Raymond Chandler tiene para la variante negra del género el mismo valor que tuvo el de Poe para la policiaca, al tratarse del primer intento de reflexión teórica. Vista con perspectiva, su aparición vino a confirmar que las características del género narrativo creado con Los crímenes de la calle Morgue estaban siendo transformadas por autores, el propio Chandler incluido, que publicaban en revistas estadounidenses pulp como Black Mask.

El simple arte de matar asume la dualidad de la modalidad narrativa que su propio autor ayudó a configurar con las narraciones protagonizadas por Philip Marlowe al reflexionar tanto sobre su vinculación con los textos policiacos -llegando a citar de forma explícita autores referenciales como Arthur ConanDoyle, Agatha Christie o Dorothy Sayers- como sobre las innovaciones aportadas. Esta dialéctica entre la tradición a la que adscribe y la nueva literatura que desarrolla es especialmente perceptible en la terminología usada por Chandler, que se refiere a las narraciones policiacas, basadas en la mera resolución racional del enigma, como «novelas de misterio clásicas» y a las suyas y las de otros escritores como Dashiell Hammett como «novelas de misterio realistas». El hecho de que las dos variantes del género solo se distingan por su adjetivo calificativo final, reservando para ambas el sintagma «novela de misterio», no solo pone de manifiesto su procedencia de un tronco común y sus semejanzas, sino también y sobre todo la deuda que ambas presentan con una serie de elementos estructurales de la narración: el punto de partida de la intriga vinculada a un acto criminal, el desarrollo basado en las pesquisas investigadoras, el hecho de que el argumento parta de la ruptura del statu quo establecido, etc.

No obstante, sobre ese fondo común, los dos tipos de novela presentan características disímiles, que Chandler resume en la mayor carga de realismo y verosimilitud que presentan las segundas. El autor, de hecho, se muestra muy crítico en el texto con la artificiosidad de la novela policiaca clásica, en la que ni los investigadores -extremadamente inteligentes, dotados de una frialdad casi inhumana y sin capacidad ninguna para emocionarse o reaccionar ante los actos que tienen que investigar, que observan solo como retos ante los que mostrar su inteligencia y no como tragedias que implican daños

\footnotetext{
${ }^{7}$ Según González de la Aleja, «existen al menos dos versiones de "The Simple Art of Murder", aparte del original publicado en la revista Atlantic Monthly en 1944: la que aparece reproducida en el libro de Howard Haycraft The Art of the Mistery Story de 1946, y la de The Simple Art of Murder, recopilación de relatos que Chandler publicó en 1950» (1996: 39).
} 
ajenos- ni los crímenes - motivados por razones a veces nimias y llevados a cabo a través de extraños y sofisticados métodos- parecen corresponderse con la realidad. Frente a ese carácter esquemático, Chandler sostiene que la novela de misterio realista -a la que tiempo después de se le denominaría «novela negra» en España- basó su nacimiento en poner a las personas «sobre el papel tal como eran, y [hacerlas] hablar y pensar en el lenguaje que solían usar en esas situaciones» (1944: 71). Para ejemplificar esta innovación, utilizó la obra de Hammett como símbolo y referencia del nuevo género, afirmando que el autor de Cosecha Roja (Red Harvest, 1929) «sacó el asesinato del jarrón veneciano y lo dejó caer en el callejón» y «devolvió el asesinato al tipo de gente que lo comete por algún motivo, no simplemente para proporcionar un cadáver; y que usan los medios que tienen a mano, no pistolas de duelo cinceladas, curare o peces tropicales» (Chandler, 1944: 71).

Sin embargo, tal y como ha señalado Manuel González de la Aleja, «el pretendido realismo comprometido de la novela negra no es ni más ni menos que una sabia combinación de fantasías universales, pesadillas históricas, problemas sociales y soluciones literarias una y otra vez repetidas» (1996: 33 $)^{8}$. Es decir, tan cierto como que Hammett dejó caer el asesinato en el callejón es que su obra bebe de referentes que, trascendiendo el mero género policiaco, se pueden identificar con otras modalidades narrativas. La multiplicidad de referentes de la novela negra se pone de manifiesto en las líneas que Chandler dedica al detective en su ensayo, en las que demuestra, al igual que Poe o Van Dine, su relevancia dentro de la nómina de personajes del género al tiempo que lo conecta con estereotipos literarios como los del caballero, el aventurero, el pícaro o el cow-boy: «[El detective] es el héroe; lo es todo. Debe ser un hombre de cabeza a los pues, a la vez un hombre corriente y un hombre especial [...]. El relato es la aventura de este hombre en busca de una verdad oculta, y no sería aventura si no le ocurriera a un hombre capaz de vivirla» (Chandler, 1944: 77 y 79).

La somera descripción que hace Chandler del modelo de investigador de la novela negra habitualmente denominado hard-boiled- vendría a confirmar, por tanto, cómo «la fórmula literaria estudia la reducción de arquetipos literarios universales a convenciones culturales muy concretas en el espacio y en el tiempo» (González de la Aleja, 1996: 30) o, lo que es lo mismo, que los personajes creados por autores como Hammett en la década de 1920 responden a los condicionamientos contextuales del momento - basados en el desmoronamiento de la fe ilimitada en la razón y en la cada vez mayor conflictividad social-, pero, al mismo tiempo, actualizan una serie de estereotipos y tópicos utilizados recurrentemente en la literatura desde tiempo inmemoriales. Se demuestra con ello la aparente paradoja de que los géneros narrativos con mayor vitalidad y mayor capacidad de perdurar y ser identificados -como el negro y policiaco- no son los que mantienen con fidelidad sus convenciones, sino, más bien, los que admiten con mayor facilidad las transformaciones y son capaces tanto de adaptarlas a cada contexto histórico como de conectarlas con el acervo cultural.

\footnotetext{
${ }^{8}$ No en vano, en la propia obra literaria de Chandler «el realismo es lírico y trascendente, porque se asienta no solo en una mirada honda del mundo, sino también en una mirada honda del arte» (Silva, 2005: 167) que se manifiesta en la estilización de la realidad, en el cuidado formal o en el lirismo de ciertos diálogos.
} 
Más allá del mero análisis teórico, Raymond Chandler, que también vertió reflexiones literarias en cartas y anotaciones personales ${ }^{9}$, intentó con El simple arte de matar dignificar el género narrativo negro y, de ese modo, dignificar su propia obra. Según Mempo Giardinelli, «a Chandler le dolía profundamente no ser reconocido como "uno de los tres grandes escritores de este país [EEUU]" (admitía solo a Faulkner y a Hemingway por encima), y no dejaba ocasión de expresarlo» (1984: 101). De ahí que en el texto se mencione de forma explícita a algunos referentes de la tradición literaria estadounidense canonizada -Walt Whitman o Hemingway, entre otros- e incluso se compare a Hammett con ellos. Chandler, consciente del desprecio con el que se juzgaba su obra y en el género al que se adscribía, «esperaba que se tendiese un puente entre la novela policial y la literatura "seria"» (MacShane, 1976: 182). No en vano, en su biografía Frank MacShane recoge unas declaraciones que expresan de forma muy sintomática y clarividente su valoración sobre la negativa percepción social que existía de la «novela de misterio realista» que él mismo ayudó a configurar:

Ni en este país [EE. UU.] ni en Inglaterra se ha producido un reconocimiento crítico de que hay mucho más arte en los mejores libros de este género que en muchos gruesos volúmenes de historia novelada o en las tonterías de significación social. La base psicológica de la inmensa popularidad de que goza entre gentes de todas clases la novela de asesinatos, crimen o misterio, aún no ha sido investigada. Se han hecho algunos intentos superficiales y otros frívolos, pero nada meticuloso, imparcial y ponderado. Este género contiene mucho más de lo que supone la gente, incluso los que están interesados en él. En general, el tema ha sido tratado con ligereza porque al parecer se ha dado por sentado, muy erróneamente, que dado que las novelas de asesinatos son de lectura fácil, son también superficiales. No son más fáciles de leer que Hamlet, Lear o Macbeth. Rayan en la tragedia y nunca son completamente trágicas. Su forma impone cierta claridad de esquema que solo se encuentra las más logradas novelas «propiamente dichas» (1976: 182).

\section{Teorías e historias del género}

Para finalizar este repaso por algunos de los textos teóricos y de las poéticas escritas por autores de novela negra y policiaca, habría que aludir a las obras de aquellos escritores que, más que reflexionar sobre su propia obra o intentar dar las principales claves temáticas y formales del género en el que se imbrican sus producciones, ofrecen una visión panorámica y diacrónica. Se trataría, en este caso, de escritores que, dejando a un lado su condición de creadores, se acercan a la literatura como estudiosos. A través de esta actitud -«pasiva», en palabras de Alfonso Reyes (1944: 56), por cuanto los sitúa en el campo del análisis, y no en el de la escritura-, autores como Howard Haycraft, Julian Symmons o Thomas Narcejac ${ }^{10}$ han escrito obras críticas sobre el género, utilizadas todavía en

\footnotetext{
${ }^{9}$ Algunas pueden leerse en El simple arte de escribir. Cartas y ensayos escogidos (1909-1959) (The Raymond Chandler Papers. Selected letters and non-fiction, 2000). Entre otros textos, Chandler llegó a escribir, en la línea de Van Dine, un decálogo normativo para componer novelas policiacas.

${ }^{10}$ En cuando a la teoría compuesta originalmente en español, habría que citar aportaciones como las de Mempo Giardinelli, Leonardo Padura, Eugenio Fuentes o Lorenzo Silva. Los dos primeros, procedentes del ámbito hispanoamericano, son los autores de, respectivamente, El género negro (1984) -una personal historia del género, muy centrada en su evolución en Estados Unidos, complementada en 2013 con una nueva edición en la que se incluye una reflexión sobre lo sucedido en las literaturas latinoamericanas-y Modernidad, posmodernidad y novela policial (2000) - un compendio de ensayos, entre los que hay análisis de obras de Chandler y Simenon o revisiones de la novela negra española e hispanoamericana, que convirtió al autor en el principal impulsor del término «neopolicial» para referirse a la literatura de género compuesta en los países americanos de habla hispana-. Fuentes, por su parte, escribió Literatura del dolor, poética de la bondad (2013), texto en el que relaciona los textos del género con algunas constantes de la literatura universal $-\mathrm{y}$, en consecuencia, con
} 
la actualidad como manuales y libros de referencia, en las que, por un lado, se ofrece una reflexión teórica que desgrana sus elementos distintivos y, por otro, se esboza una historia de la evolución del género, atendiendo tanto a sus principales hitos y transformaciones como a su relación con el resto de la literatura. Mientras que la aportación de Haycraft es recordada fundamentalmente por su carácter pionero -se publicó en 1946-, las de Symmons y Narcejac destacan por su relevancia en los ámbitos anglosajón y francófono. El primero, autor de alrededor de una treintena de novelas entre las décadas de 1940 y 1990, escribió numerosos textos teóricos sobre el género ${ }^{11}$, entre los que destacan Historia del relato policial (Bloody Murder - From the Detective Story to the Crime Novel: A History, 1972), así como monografías biográfico-críticas centradas en autores como Conan Doyle, Christie o Hammett ${ }^{12}$. El segundo, que formó tándem creativo con Pierre Boileau, es el autor de varios textos dedicados a la novela negra y policiaca, alguno centrado de forma específica en la obra de Georges Simenon. Especialmente interesante resulta Una máquina de leer: la novela policiaca (Une machine à lire: Le romanpolicier, 1975), en el que plantea una historia del género transnacional, en la que conviven diversas tradiciones, culturas, lenguas y literaturas -entre las que predominan, como es lógico, autores anglosajones y, sobre todo, franceses-. El libro presenta interesantes innovaciones, como el estudio de la relación de la novela negra y policiaca con la ética, la política o la religión, adquiriendo un valor contextual y pragmático similar al ofrecido por casi todos los acercamientos que al género se han hecho en los últimos años. Tiene, además, un marcado cariz práctico al diseccionar y aplicar los postulados teóricos al análisis de El misterio del cuarto amarillo (Le Mystère de la Chambre Jaune, 1907), de Gaston Leroux.

Sin ánimo de alguno de exhaustividad, el repaso de poéticas y propuestas teóricas desgranadas en las páginas precedentes viene a demostrar la capacidad del género negro y policiaco de dotarse a través de las aportaciones de sus propios autores de un corpus crítico y autorreflexivo. Obviando los prejuicios y las valoraciones negativas que lo relegaban casi a la condición de «subliteratura», y trascendiendo la mera crítica impresionista, los ejemplos aquí aportados demuestran cómo, durante buena parte del siglo XX, la necesidad de definir y clasificar las muestras de un corpus en continuo incremento recayó precisamente en los escritores responsables de ese aumento.

referentes de la literatura clásica o de épocas anteriores al siglo XX-, valora la obra de algunos autores concretos -Gilbert Keith Chesterton, Francisco García Pavón, Francisco González Ledesma, Stieg Larsson y el ya citado Padura-, reflexiona sobre cuestiones puntuales como la relación de la gastronomía con la novela negra y policiaca, y aporta una serie de recomendaciones a la hora de escribir basadas, fundamentalmente, en la necesidad de mantener una preocupación formal: «[Hay que] escribir una novela negra como se escribe un soneto o el ensayo más sesudo, sin hacer concesiones al mercado del presente ni a los fantasmas del futuro» (Fuentes, 2013: 97). Y Silva es autor de Líneas de sombra. Historias de policías y criminales (2005), un libro misceláneo que, entre otros textos, incluye semblanzas y análisis de las obras de Chandler y Simenon, y una poética denominada «Teoría (informal) de la novela benemérita», en la que expone las principales características y las razones de la creación de su serie narrativa protagonizada por los guardias civiles Bevilacqua y Chamorro.

${ }^{11}$ Symmons también escribió ensayos y textos de análisis sobre otros autores y tipos de literatura, como demuestran sus libros sobre Charles Dickens, Oscar Wilde o W.H. Auden.

${ }^{12}$ Otros novelistas, como Joe Gores o James Sallis, también han escrito biografías de referentes del género: Hammett en el primer caso, y David Goodis, Chester Himes y Jim Thompson en el segundo. 
Poéticas criminales: reflexiones teóricas de escritores de novela negra y policíaca

\section{Referencias bibliográficas}

Adorno, T. y HorkHEIMER, M. (1944): Dialéctica de la ilustración. Madrid, Akal, 2007.

Alonso, P. y SAntamaría, J. (1997): Antología del relato policial. Barcelona, Vicens Vives.

BoRgES, J. L.: Borges oral. Buenos Aires, Emecé.

Chandler, R. (1944): El simple arte de matar. Trad. de Jesús Ángel González López y Azucena Gonzalo Ausín. León, Universidad de León, 1996.

- (2000): El simple arte de escribir. Cartas y ensayos. Trad. de César Aira. Barcelona, Emecé, 2004.

Chesterton, G. K. (1925): Cómo escribir relatos policiacos. Trad. de Miguel Temprano. Barcelona, Acantilado, 2011.

Colmeiro, J. (1994): La novela policiaca española. Teoría e historia crítica. Barcelona, Anthropos.

ComA, J. (1985): Diccionario de la novela negra norteamericana. Barcelona, Anagrama, 1986.

Del Monte, V. (1962): Breve historia de la novela policiaca. Madrid, Taurus.

FuENTES, E. (2013): Literatura del dolor, poética de la bondad. Mérida, Editora Regional de Extremadura.

Giardinelli, M. (1984): El género negro. Buenos Aires, Capital Intelectual, 2013.

GONZÁlEZ DE LA ALEJA, M. (1996): «Introducción», en R. CHANDLER, El simple arte de matar. León, Universidad de León, pp. 9-39.

(1999): «Introducción», en M. A. RocKLAND, La cultura popular o ¿por qué estudiar basura?

La tendencia de lo vernáculo hacia lo masculino. León, Universidad de León, pp. 5-32.

Highsmith, P. (1981): Suspense. Cómo se escribe una novela de intriga. Trad. de Jordi Beltrán.

Barcelona, Anagrama, 2003.

KING, S. (1981): Danse macabre. New York, Berkeley, 1983.

MacShane, F. (1976): La vida de Raymond Chandler. Trad. de Pilar Giralt. Barcelona, Al Revés, 2017.

MARTín, A. (2007): «El género negro: esencia y personajes», en A. MARTín EsCRIBÀ y J. SÁNCHEZ

ZAPATERO, eds., Informe confidencial. La figura del detective en el género negro. Valladolid, Difácil, pp. 21-34.

(2015): Cómo escribo novela policiaca: Barcelona, Alba.

NARCEJAC, T. (1975): Una máquina de leer: la novela policiaca. Trad. de Jorge Ferreiro. México D.F., Fondo de Cultura Económica, 1986.

PAdURA, L. (2000): Modernidad, posmodernidad y novela policiaca. La Habana, Unión.

PoE, E. A. (1841): Los crímenes de la calle Morgue. Trad. de Julio Cortázar. Madrid, Alianza, 1981.

RESINA, J. R. (1997): El cadáver en la cocina. La novela criminal en la cultura del desencanto. Barcelona, Anthropos.

Reyes, A. (1944): El deslinde. Prolegómenos a la teoría literaria. Madrid. Verbum, 2014. RodRÍGUEZ PEQUEÑo, J. (2008): Géneros literarios y mundos posibles. Madrid, Envida. SILVA, L. (2005): Líneas de sombra. Historias de criminales y policías. Barcelona, Destino. 
132 Tropelías. Revista de Teoría de la Literatura y Literatura Comparada, número extraordinario 2 (2017) Javier Sánchez Zapatero

Sullá, E. (1998): «El debate sobre el canon literario», en E. Sullá, ed., El canon literario. Madrid, Arco/Libros, pp. 11-34.

Symmons, J. (1972). Historia del relato policial. Barcelona, Bruguera, 1982.

VAN Dine, S. S. [Willard Huntington Wright] (1928): «Reglas de la novela policiaca», Crítica de libros, en https://www.criticadelibros.com/metaliteratura-y-ensayo/reglas-de-la-novelapoliciaca-s-s-van-dine/ (última consulta, 17-6-2017). 